\title{
Asthma counselling targeted to removal of domestic animals
}

\author{
Louise Hagan $\mathrm{PhD}^{1}$, Pierre Valois $\mathrm{PhD}^{2}$, Hélène Patenaude $\mathrm{PhD}^{1}$, Hélène Boutin $\mathrm{MSc}^{3}$, \\ Louis-Philippe Boulet $\mathrm{MD}^{4}$, France Lafrenière $\mathrm{MSC}^{5}$
}

\begin{abstract}
L Hagan, P Valois, H Patenaude, H Boutin, L-P Boulet, F Lafrenière. Asthma counselling targeted to removal of domestic animals. Can Respir J 2008;15(1):33-38.
\end{abstract}

OBJECTIVES: To create and evaluate the efficacy of a short individualized educational intervention program, based on Prochaska's transtheoretical model, for a six-month period in a population of adult asthma patients living with domestic animals but sensitized to these pets.

METHODS: A randomized, controlled study using a pretested questionnaire was conducted at three different times (pretest, and at three and six months postintervention).

RESULTS: Eleven members (29\%) of the intervention group and eight members $(21 \%)$ of the control group removed their pets within six months $\left(\chi^{2}=3.23 ; \mathrm{P}>0.35\right)$. The two groups showed similar improvements in their perception of the benefits of pet removal and in their level of belief that they could do it. The experimental group showed a greater improvement in knowledge acquisition about asthma and allergies than the control group $(\mathrm{P}<0.05)$. Both experimental and standard educational interventions were effective in facilitating progression through the stages of behavioural change.

CONCLUSION: Overall, the results do not support the utility of behavioural change educational intervention, tailored to the transtheoretical model stage of the individual, in the context of convincing patients to remove their pets from their homes. However, the decision-making aid appears to be helpful in raising awareness of the problem of asthma and allergy in the patient, and in developing appropriate knowledge.

Key Words: Allergy; Asthma; Domestic animals; Environmental control; Psychoeducational approach

\section{Counselling sur l'asthme : Se défaire des animaux de compagnie}

OBJECTIF : Élaborer un programme court d'intervention/information individualisé et en vérifier l'efficacité selon le modèle transthéorique de Prochaska sur une période de six mois chez une population de patients asthmatiques adultes vivant avec un animal de compagnie auquel ils sont allergiques.

MÉTHODES : Étude randomisée et contrôlée reposant sur l'administration d'un questionnaire prétesté, réalisée en trois étapes (prétest, puis trois mois et six mois après l'intervention).

RÉSULTATS : Onze sujets (29\%) du groupe soumis à l'intervention et huit sujets $(21 \%)$ du groupe témoin se sont défaits de leur animal de compagnie dans les six mois $\left(\chi^{2}=3,23 ; P>0,35\right)$. Les deux groupes ont montré le même type d'amélioration quant à leur perception des avantages ressentis et quant à leur degré de conviction qu'ils arriveraient à se défaire de leur animal. Le groupe soumis à l'intervention a connu une amélioration plus marquée sur le plan de l'acquisition des connaissances sur l'asthme et sur le plan des allergies, comparativement au groupe témoin $(\mathrm{P}<0,05)$. Les deux types d'interventions (programme expérimental et programme standard) se sont révélés efficaces pour ce qui est de favoriser le passage d'une étape à la suivante en ce qui concerne le changement de comportement.

CONCLUSIONS : Dans l'ensemble, selon le modèle transthéorique, les résultats ne confirment pas l'utilité d'une intervention éducative visant à favoriser les changements de comportement adaptée au stade personnel des patients lorsqu'il est question de les convaincre de se défaire d'un animal de compagnie. Par contre, l'outil d'aide au processus décisionnel et semble sensibiliser les patients au problème de l'asthme et de l'allergie et les renseigner de manière appropriée.

U

p to $70 \%$ of patients with asthma or rhinitis are allergic to domestic animals $(1,2)$. An appropriate anti-inflammatory treatment, combined with allergen avoidance in sensitized subjects, leads to optimal asthma control $(3,4)$. Thus, in individuals with allergic asthma and evidence of allergy to pets, removal of pets is considered the best strategy to reduce asthma exacerbations $(5,6)$. Alternative measures may appear attractive - such as keeping the pet out of the asthmatic person's bedroom and cleaning the house assiduously - but they are almost always ineffective. This is because any level of allergen exposure leads to sensitization, and thus to increased asthma severity and manifestations $(7,8)$. Despite these facts, removal of the animal from the home is rarely achieved because of the strong emotional bonds that naturally form between domestic animals and their owners (9-11).

There is little research on the effect of asthma education on patients' understanding of asthma and on patients' implementation of measures to avoid environmental triggers. However, the handful of studies on the topic indicate that significant improvements can be made $(12,13)$. One randomized study (11) documented a $70.3 \%$ adoption of measures to reduce exposure to household dust mites in an education group, compared with a $0 \%$ adoption rate in a usual care group $(\mathrm{P}<0.001)$, as well as a $23 \%$ versus $15 \%$ rate of pet removal from homes of the sensitized asthma sufferers $(P>0.05)$. These gains in adherence of subjects involved in contemporary asthma education programs can be attributed to the fact that asthma education now routinely includes information about the disease and its etiology, as well as about self-management or behaviour change strategies $(12,14-16)$. However, despite the

${ }^{1}$ Faculté des sciences infirmières; ${ }^{2}$ Faculté des sciences de l'éducation, Université Laval, Quebec City; ${ }^{3}$ Direction des soins infirmiers;

${ }^{4}$ Pneumologie; ${ }^{5}$ Centre de recherche, Hôpital Laval, Sainte-Foy, Quebec

Correspondence: Dr Louise Hagan, Faculté des sciences infirmières, Université Laval, Quebec City, Quebec G1K 7P4.

Telephone 418-656-2131 ext 3505, fax 418-656-7747, e-mail louise.hagan@fsi.ulaval.ca 
effectiveness of asthma education today, the rate of compliance with measures to reduce asthma attacks is still suboptimal, particularly for the most difficult measures, such as removing pets from the home $(15,17)$.

The purpose of the present study was to evaluate whether individualized psychocognitive education could significantly affect the willingness of asthmatic adults, sensitized to domestic animals, to consent to pet removal from their homes. This educational approach is based on the transtheoretical model (TTM) of Prochaska et al $(18,19)$. It has been used by a large number of researchers and clinicians in various forms of behaviour change-focused health education. The TTM addresses the various cognitive and affective processes inherent in the five different stages of health behaviour change: stage 1, precontemplation; stage 2, contemplation; stage 3, preparation; stage 4, action; and stage 5, maintenance (18). The TTM is based on the supposition that the key predictors of whether the patient will transit the initial stages of decision-making are the weight a patient gives to the advantages versus the disadvantages of a behaviour change, and the extent of a patient's belief in his or her ability to make the decision (19).

Research and clinical observations suggest that most individuals are in stage 1 or 2 when they make an initial contact with a professional regarding health behaviour; a small number are in stage 3 (20). Prochaska et al (20) determined that when an individual moves from TTM stage 1 to 2 within one month of beginning an intervention program, he or she is twice as likely as a person who does not make the transition in that period to reach stage 5 within six months of the start of the program.

We thus hypothesized that an intervention program could positively affect a patient's transition from one TTM stage to another with respect to the decision to remove a pet from the home. Specifically, when applied to a patient with asthma who must decide whether to remove his or her pet from the home, we hypothesized that a cognitive behavioural educational intervention would facilitate the perception that the advantages of removing the animal outweighed the disadvantages. In the present study, we evaluated the utility of the intervention program in terms of the acquisition of knowledge about asthma and allergies, as well as the respective therapeutic and preventive options, and the individual's perception of his or her ability to commit to the removal of the pet.

\section{METHODS}

\section{Participants}

Patients referred to the asthma education centres of two hospitals in Quebec City, Quebec, were eligible for inclusion in the study if they attended two asthma clinics between January 1 , 2003, and December 31, 2004. Patients had to be at least 18 years of age, be able to speak and read French, and be recently diagnosed according to the Canadian asthma consensus guidelines as having poorly controlled asthma (6). Also, all eligible patients were taking inhaled corticosteroids on a continuous or intermittent schedule; had tested positive for an allergy to cat skin, dog skin and/or dander; and were living with an allergenic pet for at least two days per week. The subjects had to declare that they had some power in the decision to remove their pets from their homes. Moreover, patients were only included if they were in the precontemplation, contemplation or preparation stages of decision-making (TTM stage 1, 2 or 3 , respectively), as determined by the administration of the
University of Rhode Island Change Assessment (URICA) scale (21). The URICA scale is made up of six questions, each with a 'yes' or 'no' answer, with the overall balance providing a determination of the TTM stage the patient has reached. The URICA scale was determined to be moderately reliable in a test-retest study of 2629 subjects (22).

Patients were excluded if they had been involved in an asthma education program in the previous six months, if they were diagnosed as being an alcoholic and/or having a substance abuse disorder, if they had any other psychiatric diagnosis, if they had demonstrated intellectual impairment or if they had any other condition that could significantly limit their cognitive abilities.

Seventy-eight subjects met the inclusion criteria. The relevant ethics committees approved the study design, and informed consent was obtained from all the participants. They were randomly assigned, one-to-one, to an experimental group or to a control group by a research assistant using a random numbers table.

\section{Intervention}

The educational intervention consisted of two 60 min visits conducted one month apart. They involved one-on-one meetings between each patient and an asthma care nurse clinician trained in the educational intervention. In the first visit, the nurse clinician established a relationship of trust with the participants. The nurse clinician also outlined the study design and the intervention; the latter was tailored to each patient's specific stage of behavioural change, as measured by the URICA scale. Participants were given a brochure that provided general information on asthma and allergies, and that contained questions on the patient's knowledge about the effects of pets on asthmatic patients sensitized to animals and questions on their ability to part with their pet. This brochure served as a 'decision aid' and an educational tool. In the second visit, subjects were asked to discuss their thoughts that arose while reading the brochure and while answering the questions in it. Their shift in decision-making stage since the first visit was also recorded by the nurse clinician using the URICA scale.

The nurse clinician then provided each patient with asthma education tailored to his or her TTM stage. The aim of the intervention was to influence processes of change, which are activities that people use to progress through the stages. Processes of change provide important guides for intervention. The first processes are classified as experiential processes and are used primarily for the early stage transition. In the present study, adult asthmatic patients were all in the three early stages. The targeted experiential processes were consciousness raising, dramatic relief, environmental re-evaluation and selfre-evaluation. For example, the nurse clinician focused the education of patients in the precontemplation stage on consciousness raising and increased knowledge about asthma symptoms and allergens associated with pets, as well as on emotional support to help them begin to contemplate parting with their pets. The nurse clinician focused the education of patients in the contemplation stage on increasing their awareness of the significant negative impacts of cohabitation with a pet and of the salubrious effect of the removal of the pet from their environment. This was aimed at tipping the balance of the patients' perceptions toward more advantages than disadvantages of removing their pets. However, the nurse clinician did not tell the patients at either the first or second visit to 
remove their domestic animals. Rather, she focused on increasing the patients' knowledge and emotional preparedness according to their particular TTM stage. She also discussed strategies to address the 'cons' of removing the pet and to reduce barriers to removing the pet. For example, she discussed alternatives to the animal company or attachment, or ways to reduce family resistance to pet removal.

At the conclusion of the first and second visits, the nurse clinician measured the patients' respiratory capacity with a peak flow meter.

Members of the control group also participated in two 60 min visits held one month apart. The visits were identical to those given to the intervention group in three aspects: the establishment of trust between the nurse clinician and participant, an explanation by the nurse clinician of the study design, and time for patients to discuss and receive feedback about their feelings regarding the removal of pets from their homes. The visits also differed in three aspects from those in the intervention group. One difference was that the brochure was neither given to nor discussed by the patients. Rather, the patients were simply given a general brochure on environmental allergens. A second difference was that the asthma education was not tailored to the patient's stage of decision-making. Rather, the patient was given the basic facts about asthma, allergy and pet cohabitation. This type of educational intervention corresponds with usual practice in asthma clinics in Quebec and across Canada. The third aspect of the visits that differed from those in the intervention group was that the members of the control group were directly recommended by the nurse clinician to remove their domestic animals from their homes. If they seemed disinclined to do so, they were given suggestions on alternative measures to reduce asthma exacerbations. This was not the case for the experimental group, so as to respect principles of a more individualized and humanistic educational approach, and to adapt interventions to specific processes of change with which patients were involved.

\section{Questionnaires}

Demographic characteristics - level of education, family status and place of recruitment - were recorded at baseline. Six additional pieces of information were gathered at baseline: duration of the patient's asthma; number of hospitalizations and/or visits to an emergency room in the previous six months; whether he or she was previously a recipient of asthma education; whether they had previously lost or grieved for a pet; whether they had sole responsibility for the decision of whether to remove the current pet from the home; and degree of attachment to the pet. The degree of attachment was measured using an adaptation of the Pet Attitude Scale (23). Six of 18 items from the scale were used. Patients were found to have a high internal consistency at enrolment, with Cronbach's alpha equal to 0.74 . The scores can range from 0 to 6 , with 0 indicating no attachment and 6 indicating a high degree of attachment to the pet.

Part of the questionnaire comprised 21 questions: 11 questions on various advantages of parting with the pet, and 10 questions on various disadvantages of parting with the pet. Advantages and disadvantages were identified from a previous qualitative research study conducted on a sample of 20 adult asthmatic patients. Patients were able to choose from responses ranging from 1 to 6 for each question, with 1 being 'strongly disagree' and 6 being 'strongly agree'. A pretest of those items showed good internal consistancy (Cronbach's alpha was 0.83 for advantages and 0.85 for disadvantages). The resulting score provided a snapshot of the number of advantages and disadvantages to which each patient subscribed at the time he or she completed the questionnaire, and how strongly the patient subscribed to them.

Here are a few examples of the advantages of parting with the pet, which were mesasured: less costs for asthma medication, less visits to the emergency department, better respiratory health, cleaner house, more freedom for leisure, etc. Among the disadvantages of parting with the pet that were measured were feelings of loneliness, sadness, forced mourning, family tension, guilt, etc.

Another part of the questionnaire comprised 25 true or false questions on the patient's knowledge of asthma and allergies. Each correct response was given one point, and total scores were translated into percentages; thus, the maximum possible percentage was $100 \%$.

The questionnaire also included the following three statements, corresponding to the behavioural change stages of the URICA scale, each with an 'agree' or 'disagree' response:

- I cannot envisage departing from my pet for now.

- I know that my pet could worsen my asthma, and I will eventually consider parting with him. However, I take no initiative to do so.

- I considered parting from my pet soon and have even taken some initiatives to do so.

At three and six months, a question was aimed at verifying whether the individual still lived with or had departed from his pet. This scale was inspired from a URICA algorithm $(18,20)$.

A final part of the questionnaire measured perceived selfefficacy related to the idea of departing from the animal. To do so, six items were developed using a range of 10-degree scales.

\section{Subject profile}

\section{RESULTS}

Thirty-eight patients were randomized to the intervention group and the other 38 to the control group. One patient in each group did not complete the study because of a lack of time and/or reluctance to participate for other reasons.

As shown in Tables 1 and 2, the two groups were comparable in most disease and demographic characteristics, as well as in their perceived ability to part with their pet and degree of attachment to their pet. However, a significantly greater proportion of the control group had previously grieved for a pet ( $35.2 \%$ versus $\left.13.2 \% ; \chi^{2}=4.96 ; \mathrm{P}<0.03\right)$, while a significantly greater proportion of members of the experimental group had sole authority over whether to remove or keep their pets (63.2\% versus $\left.39.5 \% ; \chi^{2}=4.27 ; \mathrm{P}<0.04\right)$.

Review of audiotapes of patient encounters with the nurse clinician indicated that patients in both groups received similar educational information on asthma and allergy, as well as on the effects of pet allergens on respiratory function.

\section{Progression through behavioural stages}

The internal consistency of the six scales in the questionnaire was measured using Cronbach's alpha at each of the three time periods. The results revealed that the scales were all highly reliable at all times (alpha greater than 0.70 for all six collectively), with one exception: the reliability of the scale on the 
TABLE 1

Subject profile for control variables

\begin{tabular}{lcc}
\hline Control variables & $\begin{array}{c}\text { Control group, } \\
\text { mean } \pm \text { SD }\end{array}$ & $\begin{array}{c}\text { Experimental group, } \\
\text { mean } \pm \text { SD }\end{array}$ \\
\hline Most recent peak flow result, \% & $87.4 \pm 15.57$ & $89.6 \pm 18.02$ \\
Duration of asthma, months & $124.5 \pm 138.90$ & $158.2 \pm 134.38$ \\
Degree of morbidity, $n$ & & 0.57 \\
Emergency room visits in the previous six months & $0.63 \pm 0.91$ & 0.29 \\
Hospitalization in the previous six months & $0.03 \pm 0.16$ & $0.55 \pm 0.80$ \\
Frequency of use of inhaled corticosteroids per day & $0.39 \pm 0.68$ & 0.69 \\
Perceived ability to part with the pet ${ }^{*}$ & $5.7 \pm 1.99$ & $0.37 \pm 0.54$ \\
Degree of attachment to the pet ${ }^{\dagger}$ & $4.9 \pm 1.62$ & $5.6 \pm 2.38$ \\
\hline
\end{tabular}

* Likert scale with a range of 10 degrees from 0 to 10, rating agreement or disagreement; ${ }^{\dagger}$ Rating scale with a range of 0 to 6 , rating degree of attachment for six selected items from the Pet Attitude Scale

TABLE 2

Sociodemographic characteristics

\begin{tabular}{|c|c|c|c|}
\hline Control variables & $\begin{array}{c}\text { Control } \\
\text { group, } \\
n(\%) \\
(n=38)\end{array}$ & $\begin{array}{c}\text { Experimental } \\
\text { group, } \\
n(\%) \\
(\mathrm{n}=\mathbf{3 8})\end{array}$ & $\mathbf{P}$ \\
\hline Sex & & & 0.59 \\
\hline Female & $30(78.9)$ & $28(73.7)$ & \\
\hline Male & $8(21.1)$ & $10(26.3)$ & \\
\hline Age category, years & & & 0.48 \\
\hline $18-24$ & $9(23.7)$ & $4(10.5)$ & \\
\hline $25-34$ & $14(36.8)$ & $15(39.5)$ & \\
\hline $35-44$ & $9(23.7)$ & $8(21.1)$ & \\
\hline $45-54$ & $3(7.9)$ & $6(15.8)$ & \\
\hline $55-64$ & $3(7.9)$ & $5(13.2)$ & \\
\hline Highest level of education completed & & & 0.14 \\
\hline Primary school & $0(0)$ & $1(2.6)$ & \\
\hline Secondary school & $14(36.8)$ & $7(18.4)$ & \\
\hline College & $8(21.1)$ & $15(39.5)$ & \\
\hline University & $16(42.1)$ & $15(39.5)$ & \\
\hline Family status & & & 0.19 \\
\hline Alone & $6(15.8)$ & $6(15.8)$ & \\
\hline With or without spouse, with children & $14(36.8)$ & $11(28.9)$ & \\
\hline With spouse, without children & $8(21.1)$ & $17(44.7)$ & \\
\hline With parent(s) & $5(13.2)$ & $2(5.3)$ & \\
\hline Other & $5(13.2)$ & $2(5.3)$ & \\
\hline Place of recruitment & & & 0.59 \\
\hline Asthma education centre 1 & $30(79.0)$ & $28(73.7)$ & \\
\hline Asthma education centre 2 & $8(21.0)$ & $10(26.3)$ & \\
\hline Received asthma education & & & 0.60 \\
\hline Yes & $29(76.3)$ & $27(71.1)$ & \\
\hline No & $9(23.7)$ & $11(28.9)$ & \\
\hline Experience with grieving for a pet & & & 0.03 \\
\hline Yes & $13(35.2)$ & $5(13.2)$ & \\
\hline No & $24(64.8)$ & $33(86.8)$ & \\
\hline \multicolumn{2}{|c|}{ Decision-making power on removal of the pet } & & 0.04 \\
\hline Total & $15(39.5)$ & $24(63.2)$ & \\
\hline Shared with one or more individuals & $23(60.5)$ & $14(36.8)$ & \\
\hline
\end{tabular}

patient's knowledge of asthma and allergies at three months after the meetings was only moderately reliable (alpha $=0.66)$.

Table 3 presents each group's movement from one TTM stage to another, based on scores on the TTM-based, pet
TABLE 3

Stages of behaviour change throughout the study

\begin{tabular}{lccc}
\hline & \multicolumn{3}{c}{ Stage, mean \pm SD } \\
\cline { 2 - 4 } Group & Baseline & Three months & Six months \\
\hline Control & $1.37 \pm 0.54^{\mathrm{a}}$ & $1.76 \pm 0.97^{\mathrm{b}}$ & $2.16 \pm 1.17^{\mathrm{b}}$ \\
Experimental & $1.34 \pm 0.53^{\mathrm{a}}$ & $1.82 \pm 1.14^{\mathrm{b}}$ & $2.13 \pm 1.32^{\mathrm{b}}$ \\
Total & $1.36 \pm 0.54$ & $1.79 \pm 1.05$ & $2.14 \pm 1.24$
\end{tabular}

Means in the same row or column that do not share superscripts differ at $P<0.05$

removal-focused scale. Both groups' average stage increased from 1 to 2: the intervention group progressed from 1.34 to 1.82 at three months, then to 2.13 at six months; the control group progressed from 1.37 to 1.76 at three months, then to 2.16 at six months. Results of ANOVA with repeated measures (procedure mixed) indicated that the two groups progressed at the same rate through the stages of behavioural change. Moreover, the association of group with time was not significant.

Eleven members (29\%) of the intervention group and eight members $(21 \%)$ of the control group divested themselves of their pets by the end of the study. The difference was, however, not statistically significant $\left(\chi^{2}=3.23 ; \mathrm{P}>0.35\right)$.

Quality of the decision-making process

Table 4 presents some of the results of the quality of the decisionmaking process: the average number of perceived advantages and disadvantages of parting with a pet, and knowledge of asthma and allergies. ANOVA with repeated measures demonstrated that neither the experimental group nor the control group experienced a significant increase in the average number of perceived disadvantages of pet removal from baseline, compared with three or six months postintervention. Furthermore, the association of group with time was not significant $(\mathrm{F}=0.57$; $\mathrm{P}=0.56$ ). Because the disadvantages measured were mainly feelings associated with the idea of parting with the pet, those affective attributes may be more stable or less susceptible to being influenced in the short term than cognitive attributes, which were used to characterize the perceived advantages.

However, the average number of advantages subscribed to by members of each group did change appreciably over time in both groups to approximately four - from 3.56 to 3.82 in the control group and from 3.65 to 4.10 in the intervention group $(\mathrm{P}<0.001$ for both). Four advantages were the time and money 
TABLE 4

Quality of the decision-making process

\begin{tabular}{llcc}
\hline \multirow{2}{*}{ Group } & \multicolumn{3}{c}{$\begin{array}{c}\text { Number of perceived advantages of removal } \\
\text { of the pet from the home, mean } \pm \text { SD }\end{array}$} \\
\cline { 2 - 4 } Control & Baseline & Three months & Six months \\
Experimental & $3.56 \pm 0.91^{\mathrm{a}}$ & $3.82 \pm 1.04^{\mathrm{b}}$ & $3.90 \pm 1.10^{\mathrm{b}}$ \\
Total & $3.65 \pm 0.97^{\mathrm{a}}$ & $4.10 \pm 0.94^{\mathrm{b}}$ & $4.13 \pm 0.91^{\mathrm{b}}$ \\
& $3.61 \pm 0.94$ & $3.96 \pm 0.99$ & $4.01 \pm 1.01$ \\
& Number of perceived disadvantages associated \\
Group & \multicolumn{2}{c}{ with the removal of the pet, mean \pm SD } \\
\hline Control & Baseline & Three months & Six months \\
Experimental & $4.39 \pm 0.88^{\mathrm{a}}$ & $4.33 \pm 1.00^{\mathrm{a}}$ & $4.25 \pm 1.20^{\mathrm{a}}$ \\
Total & $4.23 \pm 1.45^{\mathrm{a}}$ & $4.36 \pm 1.18^{\mathrm{a}}$ & $4.52 \pm 1.31^{\mathrm{a}}$ \\
& $4.31 \pm 1.20$ & $4.34 \pm 1.09$ & $4.38 \pm 1.25$ \\
Group & \multicolumn{4}{c}{ Knowledge of asthma, mean \pm SD } \\
\hline Control & Baseline & Three months & Six months \\
Experimental & $0.53 \pm 0.19^{\mathrm{a}}$ & $0.70 \pm 0.14^{\mathrm{b}}$ & $0.71 \pm 0.15^{\mathrm{b}}$ \\
Total & $0.55 \pm 0.16^{\mathrm{a}}$ & $0.79 \pm 0.10^{\mathrm{b}}$ & $0.78 \pm 0.13^{\mathrm{b}}$ \\
\hline
\end{tabular}

Means in the same row or column that do not share superscripts differ at $P<0.05$

saved from having to care for the pet, the salubrious effect on the patient's respiratory health, and the resultant reductions in both medication costs and emergency room visits. The results did not change after controlling for whether the patient had previously grieved for a pet, and for the degree to which the patient had autonomy over the decision to remove the pet from the home - ie, the two variables for which the two groups differed at the start of the study.

The average percentage level of knowledge of asthma and allergy increased at the same rate in the two groups, and occurred in parallel with the move from TTM stage 1 to 2: the average level of knowledge increased from 0.53 to 0.70 in the control group and from 0.55 to 0.79 in the experimental group. The difference in percentage scores of the two groups was statistically significant $(\mathrm{P}<0.05)$. These results did not vary after controlling for previous experience with grieving for a pet and degree of autonomy over removal of the pet. There was also a significant difference between the two groups at three and six months in perceived self-efficacy to remove the pet.

\section{DISCUSSION}

The results of the study reveal a statistically significant progression through the TTM stages of behavioural change, according to the URICA scale, three and six months after members of both the experimental and control groups met with a nurse clinician. The study was six months long, a period that is sufficiently short to fit within the rigours of busy clinics but, as documented by Prochaska et al (20) and Boulet et al (24), sufficiently long to observe some progression in subjects' TTM stages. The fact that there was a progression in TTM stages, and also an increase in self-efficacy and belief in more advantages (pros) of removing pets, indicates that the overall study design was adequate. Indeed, as demonstrated in other studies (20), there was a significant difference at both three and six months postintervention for the two groups combined (experimental and control groups) between the average number of advantages subscribed to by patients when stages 1 or 2
TABLE 5

Perceived pros and cons for pet removal, knowledge and perceived self-efficacy, according to combined stages of behaviour change measured at the time points

\begin{tabular}{lcc}
\hline & \multicolumn{2}{c}{ Baseline, mean \pm SD } \\
\cline { 2 - 3 } Variables & Stages 1 and 2 & Stages 3 and 4 \\
\hline Pros, $\mathrm{n}$ & $3.81 \pm 0.93$ & $4.58 \pm 1.04^{*}$ \\
Cons, $\mathrm{n}$ & $4.42 \pm 1.08$ & $4.03 \pm 1.08$ \\
Knowledge & $0.74 \pm 0.13$ & $0.79 \pm 0.13$ \\
Self-efficacy & $5.54 \pm 1.93$ & $7.59 \pm 1.34^{*}$ \\
Variables & \multicolumn{1}{c}{ Three months, mean \pm SD } \\
\hline Pros, $\mathrm{n}$ & Stages 1 and 2 & Stages 3 and 4 \\
Cons, $\mathrm{n}$ & $3.79 \pm 0.90$ & $4.46 \pm 1.08^{*}$ \\
Knowledge & $4.58 \pm 1.19$ & $4.01 \pm 1.30$ \\
Self-efficacy & $0.73 \pm 0.16$ & $0.78 \pm 0.12$ \\
\hline
\end{tabular}

*Stages 1 and 2 versus stages 3 and 4, $P<0.05$

(precontemplation and contemplation, respectively) were combined, and the number subscribed to by patients in stages 3 and 4 (preparation and action, respectively) $(\mathrm{P}<0.05)$ (Table 5). In the same way, we also observed an increased self-efficacy score for patients at the higher stages of change.

However, progression to the point of being ready to actually remove a pet may require longer than a period of six months. This is because when most people prepare to part from a pet, they are anticipating a mourning process and hence subsequently require significant emotional support. Hence, the nonsignificant difference in progression in TTM stages between the experimental and control groups may have become significant if the study was longer. Conversely, it may not have become significant considering the high degree of attachment to the pet in both groups (Table 1). This may, in fact, be one of the most important barriers that educators face when discussing issues related to parting with a beloved domestic animal. Finaly, in somes cases, family tension involved with the decision to depart from their pet is also an important issue for educators, and it requires time and negotiation strategy.

Only by conducting further research can one determine whether the surprising result of similar progressions in TTM stages by both groups, as well as similar increases in knowledge of asthma and allergy, are a result of ineffectiveness of the intervention or of exposure by the control group to factors that gave its members many of the advantages of the intervention group. There are certainly several reasons for the latter to be the case. For example, subjects in both groups were sensitized to issues surrounding pet allergens in a caring manner by nurse clinicians. Furthermore, all patients were required three times with each administration of the questionnaire - to reflect on their knowledge of asthma and allergy, the advantages and disadvantages of keeping pets to which they were sensitive, and their ability to part with the pet. The observed significantly higher mean scores on knowledge (Table 4) for the experimental group may, however, demonstrate added value from systematic use of a decision-making educational tool.

The comparable progression of the experimental and control groups must also be due, in part, to the assistance of educators, who had considerable experience and competence in the application of asthma education programs. Their abilities 
and convincing attitude, independent of the duration of the intervention and use of the systematic decision-making tool, likely had an influence on the subjects' perceptions of the advantages of parting with the pet and on the subjects' feelings of self-efficacy to do so.

It is also important to note that both control and experimental groups were selected from a client base of two asthma education centres. In Quebec, there are more than 100 of these centres. They were founded in the late 1990s and integrated into hospitals or community health centres, with the specific mission to provide asthma education to patients. Consequently, even if the research design of the present study carefully differentiated between the intervention and the control conditions, strict control over educators' attitudes and words used was practically impossible on a daily basis in the

\section{REFERENCES}

1. Canadian Institute for Health Information, Canadian Lung Association, Health Canada, Statistics Canada. Respiratory Disease in Canada, 1st edn. Ottawa: Health Canada, 2001.

2. Boulay ME, Boulet LP. The relationships between atopy, rhinitis and asthma: Pathophysiological considerations. Curr Opin Allergy Clin Immunol 2003;3:51-5.

3. Björnsdottir US, Jakobinudottir S, Runarsdottir V, Juliusson S. The effect of reducing levels of cat allergen (Fel d 1) on clinical symptoms in patients with cat allergy. Ann Allergy Asthma Immunol 2003;91:189-94.

4. van der Heide S, van Aalderen WM, Kauffman HF, Dubois AE, de Monchy JG. Clinical effects of air cleaners in homes of asthmatic children sensitized to pet allergens. J Allergy Clin Immunol 1999;104:447-51.

5. Boulet LP, Bai TR, Becker A, et al. What is new since the last (1999) Canadian asthma consensus guidelines? Can Respir J 2001;8(Suppl A):5A-27A.

6. Lemière $\mathrm{C}$, Bai $\mathrm{T}$, Balter $\mathrm{M}$, et al. Adult asthma consensus guidelines update 2003. Can Respir J 2004;11(Suppl A):9A-18A.

7. Wood RA, Mudd KE, Eggleston PA. The distribution of cat and dust mite allergens on wall surfaces. J Allergy Clin Immunol 1992;89:126-30.

8. Berge M, Munir AK, Dreborg S. Concentrations of cat (Fel d 1), $\operatorname{dog}($ Can $\mathrm{f} 1$ ) and mite (Der $\mathrm{f} 1$ and Der $\mathrm{p} 1$ ) allergens in the clothing and school environment of Swedish schoolchildren with and without pets at home. Pediatr Allergy Immunol 1998;9:25-30.

9. Mathur SK, Busse WW. Asthma: Diagnosis and management. Med Clin North Am 2006;90:39-60.

10. Desjardins A, Benoît C, Ghezzo H, et al. Exposure to domestic animals and risk of immunologic sensitization in subjects with asthma. J Allergy Clin Immunol 1993;91:979-86.

11. Côté J, Cartier A, Robichaud P, et al. Influence of asthma education on asthma severity, quality of life and environmental control. Can Respir J 2000;7:395-400.

12. Boulet LP. Asthma education: What has been its impact? Can Respir J 1998;5(Supp A):91A-6A. clinical setting. Thus, it may be fruitful to repeat the present study with more stringently defined and differentiated control and intervention groups.

\section{CONCLUSIONS}

Overall, the results do not support the utility of a behavioural change educational intervention, tailored to the TTM stage of the individual, in the context of convincing patients to remove their pets from their homes. However, the decisionmaking aid appears to be helpful in raising awareness of the problem of asthma and allergy in the patient, and in developing appropriate knowledge.

FUNDING: This study was supported by a grant from VESPA/FRSQ.

13. Bush RK. Environmental controls in the management of allergic asthma. Med Clin North Am 2002;86:973-89.

14. Gibson PG, Powell H, Coughlan J, et al. Self-management education and regular practitioner review for adults with asthma. Cochrane Database Syst Rev 2002:CD001117.

15. Gibson PG, Powell H, Coughlan J, et al. Self-management education and regular practitioner review for adults with asthma. Cochrane Database Syst Rev 2007:CD001117.

16. van der Palen J, Klein JJ, Zielhuis GA, van Herwaarden CL, Seydel ER. Behavioural effect of self-treatment guidelines in a self-management program for adults with asthma. Patient Educ Couns 2001;43:161-9.

17. McGhan SL, Cicutto LC, Befus AD. Advances in development and evaluation of asthma education programs. Curr Opin Pulm Med 2005;11:61-8.

18. Prochaska JO, DiClemente CC, Norcross JC. In search of how people change. Applications to addictive bahaviors. Am Psychol 1992;47:1102-14.

19. Prochaska JO, Norcross JC, DiClemente CC. Changing For Good. A Revolutionary Six-Stage Program for Overcoming Bad Habits and Moving Your Life Positively Forward. New York: Avon Books Inc, 1994.

20. Prochaska JO, Velicer WF, Rossi JS, et al. Stages of change and decisional balance for 12 problem behaviors. Health Psychol 1994;13:39-46.

21. Cassidy CA. Using the transtheoretical model to facilitate behavior change in patients with chronic illness. J Am Acad Nurse Pract 1999;11:281-7.

22. Donovan RJ, Jones S, Holman CD, Corti B. Assessing the reliability of a stage of change scale. Health Educ Res 1998;3:285-91.

23. Wilson CC, Netting FE, New JC. The Pet Attitude Inventory. Anthrozoös 1987;1:76-84.

24. Boulet LP, Becker A, Bérubé D, Beveridge R, Ernst P. Canadian asthma consensus report, 1999. Canadian Asthma Consensus Group. CMAJ 1999;161(11 Suppl):S1-S6. 


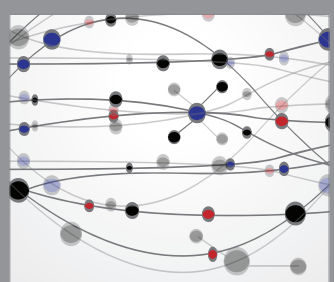

The Scientific World Journal
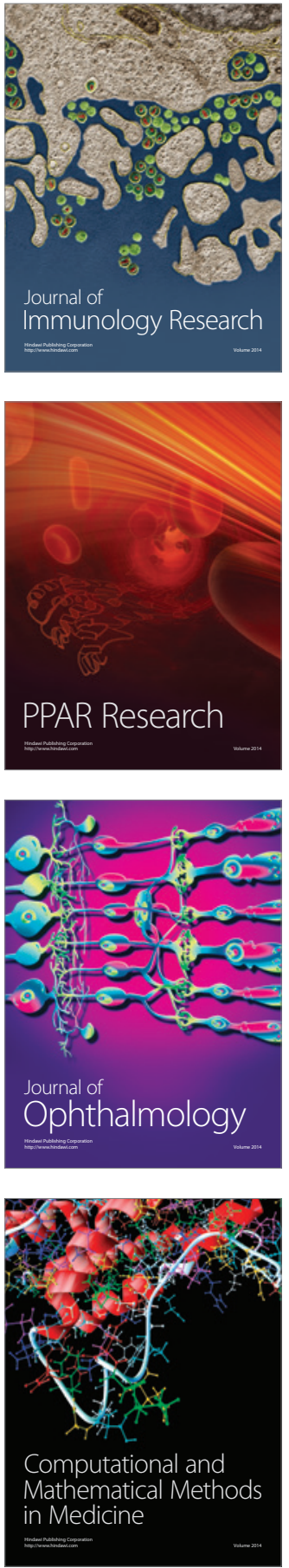

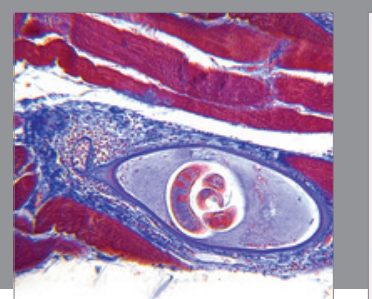

Gastroenterology Research and Practice

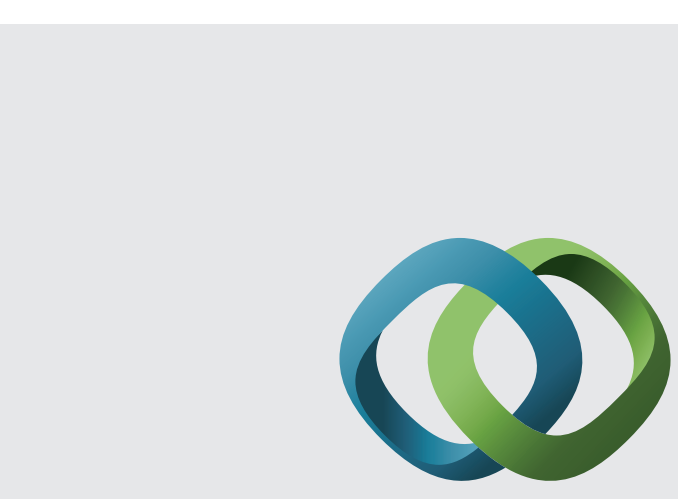

\section{Hindawi}

Submit your manuscripts at

http://www.hindawi.com
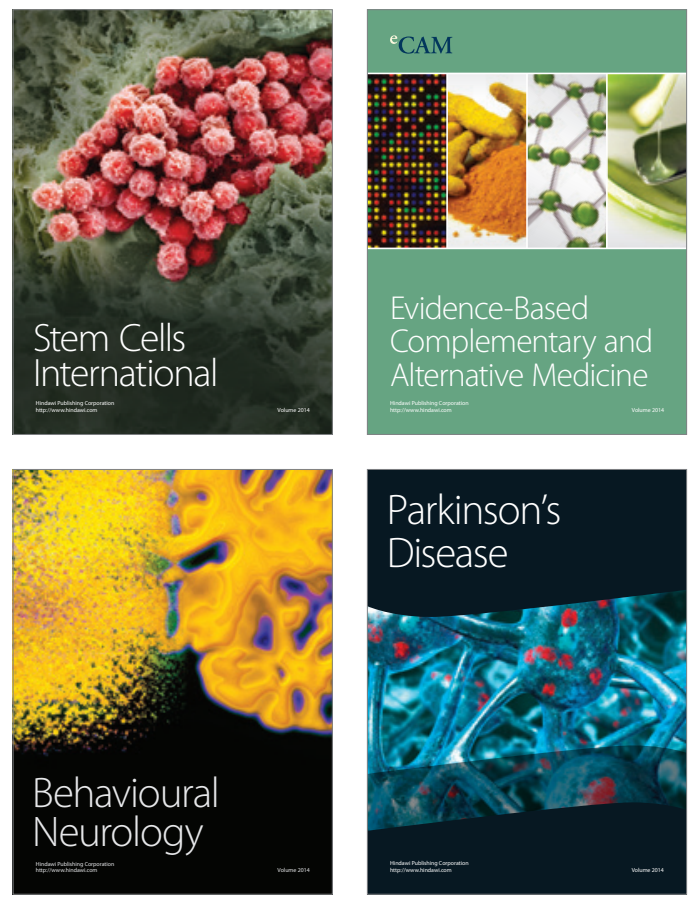
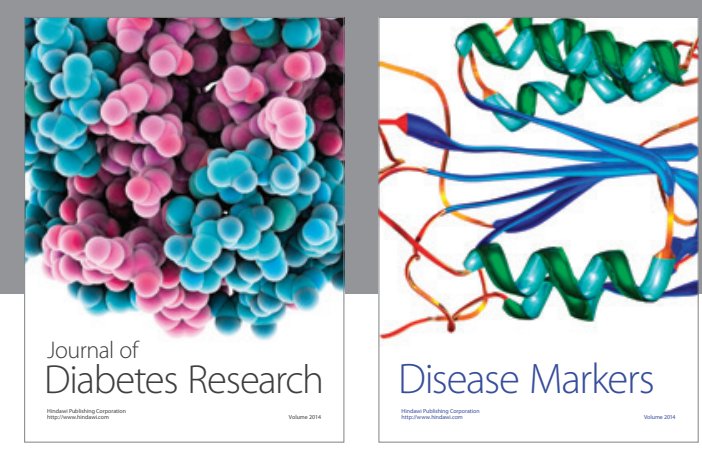

Disease Markers
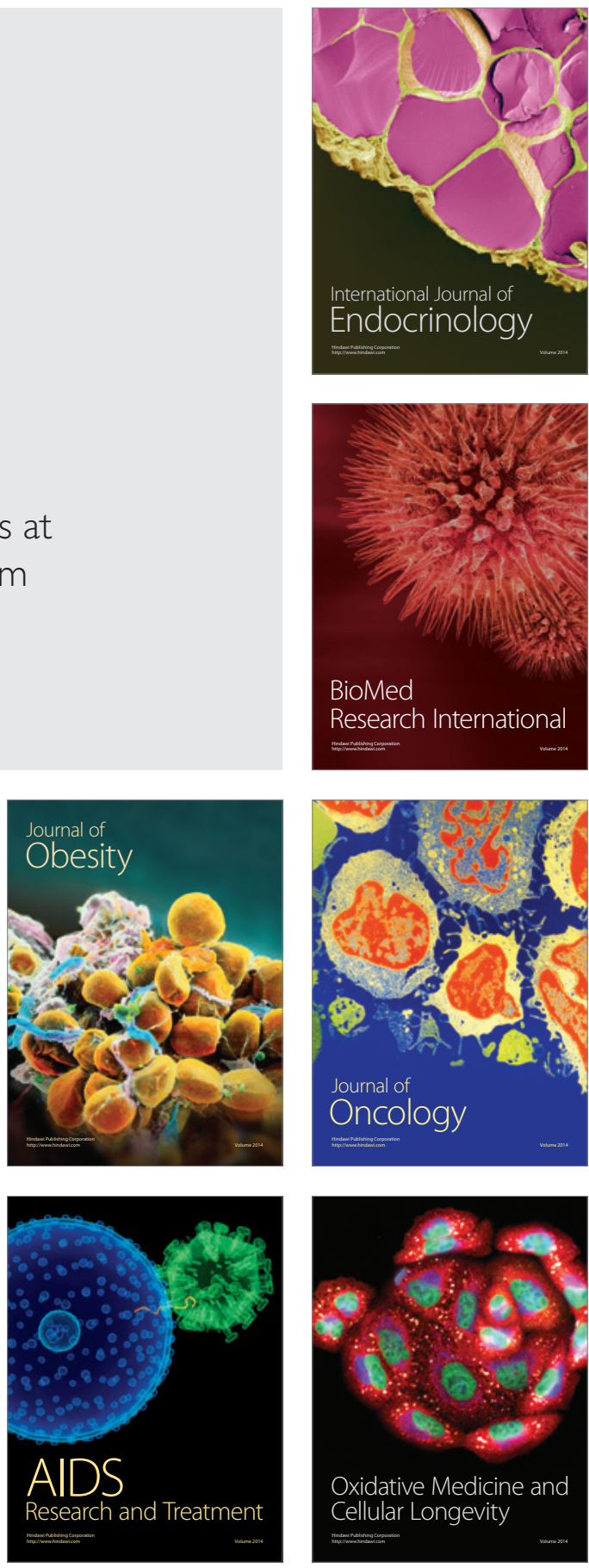